Meta

Journal des traducteurs

Translators' Journal

\title{
Hispanoamérica desde fuera: la investigación en traducción de tema hispanoamericano publicada en revistas no hispanoamericanas
}

\section{Francisco Javier Vargas Gómez}

Volume 64, numéro 2, août 2019

URI : https://id.erudit.org/iderudit/1068203ar

DOI : https://doi.org/10.7202/1068203ar

Aller au sommaire du numéro

\section{Éditeur(s)}

Les Presses de l’Université de Montréal

\section{ISSN}

0026-0452 (imprimé)

1492-1421 (numérique)

\section{Découvrir la revue}

Citer cet article

Vargas Gómez, F. J. (2019). Hispanoamérica desde fuera: la investigación en traducción de tema hispanoamericano publicada en revistas no hispanoamericanas. Meta, 64(2), 467-490. https://doi.org/10.7202/1068203ar
Résumé de l'article

En s'appuyant sur les informations pertinentes dans BITRA (base de données multilingue à accès libre qui comprend plus de 70000 références bibliographiques dans le domaine), une étude bibliométrique a été réalisée pour définir l'évolution et l'état de la question de la recherche traductologique sur l'Amérique hispanique publié dans des revues non hispaniques. Des techniques pour le comptage des publications (Grbić y Pöllabauer 2008c ; Li 2015 ; Martínez-Gómez 2015) ont été appliquées sur un corpus de 611 articles publiés dans 193 revues non hispano-américaines pour examiner différents indicateurs de production. Les résultats révèlent une augmentation de l'intérêt sur l'Amérique hispanique, des taux de productivité et de la fréquence des publications en collaboration principalement à partir des années 1990, aussi bien que la prédominance des thèmes littéraires, des études de cas et des questions historiques, le favoritisme de l'anglais, de l'espagnol et des revues spécialisées, et le positionnement des États-Unis et de l’Espagne comme principaux centres de publication. 


\title{
Hispanoamérica desde fuera: la investigación en traducción de tema hispanoamericano publicada en revistas no hispanoamericanas
}

\author{
FRANCISCO JAVIER VARGAS GÓMEZ \\ Universidad Nacional, Heredia, Costa Rica* \\ vargasgomezfrancisco@gmail.com
}

\section{RÉSUMÉ}

En s'appuyant sur les informations pertinentes dans BITRA (base de données multilingue à accès libre qui comprend plus de 70000 références bibliographiques dans le domaine), une étude bibliométrique a été réalisée pour définir l'évolution et l'état de la question de la recherche traductologique sur l'Amérique hispanique publié dans des revues non hispaniques. Des techniques pour le comptage des publications (Grbić y Pöllabauer 2008c; Li 2015; Martínez-Gómez 2015) ont été appliquées sur un corpus de 611 articles publiés dans 193 revues non hispano-américaines pour examiner différents indicateurs de production. Les résultats révèlent une augmentation de l'intérêt sur l'Amérique hispanique, des taux de productivité et de la fréquence des publications en collaboration principalement à partir des années 1990, aussi bien que la prédominance des thèmes littéraires, des études de cas et des questions historiques, le favoritisme de l'anglais, de l'espagnol et des revues spécialisées, et le positionnement des États-Unis et de l'Espagne comme principaux centres de publication.

\begin{abstract}
Drawing upon relevant information from BITRA (an open access multilingual database with more than 70000 bibliographic references in the field), a bibliometric study was conducted to depict the evolution and the state of the art of translation studies on Hispanic America published in journals outside the region. Publication count methods (Grbić y Pöllabauer 2008c; Li 2015; Martínez-Gómez 2015) were applied over a corpus of 611 articles published in 193 non-Hispanic American journals to examine different productivity indicators. The results reveal an increase of the interest over Hispanic America, of productivity rates and of co-authorship frequency mainly from the 1990s on. Results also point to the predominance of literary themes, case studies and historical issues, the favoring of English, Spanish and specialized journals when it comes to publishing, and the positioning of the United States and Spain as the main publication hubs.
\end{abstract}

\section{RESUMEN}

Se realizó un estudio bibliométrico a partir de la información pertinente disponible en BITRA (base de datos multilingüe de acceso libre con más de 70000 referencias bibliográficas en el campo) para delimitar la evolución y el estado de la cuestión de la investigación en traducción sobre Hispanoamérica publicada en revistas no hispanoamericanas. Se aplican técnicas de conteo de publicaciones (Grbić y Pöllabauer 2008c; Li 2015; Martínez-Gómez 2015) a un corpus de 611 artículos publicados en 193 revistas y se examinan diferentes indicadores de productividad. Los resultados revelan un aumento del interés por la región hispanoamericana, de la productividad y de la coautoría principalmente a partir de los años noventa. También se observa el predominio de los temas literarios, estudios de caso y asuntos históricos, la preferencia por el inglés, el español y las revistas especializadas, y el posicionamiento de los Estados Unidos y España como principales centros de publicación. 


\section{MOTS CLÉS/KEYWORDS/PALABRAS CLAVE}

Amérique hispanique, études de traduction, bibliométrie, revues, articles Hispanic America, translation studies, bibliometrics, journals, articles Hispanoamérica, estudios de traducción, bibliometría, revistas, artículos

\section{Introducción}

Los estudios de traducción e interpretación (ETI) sobre Hispanoamérica ${ }^{1}$ existen al menos desde 1932 y la gran mayoría de las investigaciones sobre el tema divulgadas en revistas se ha publicado fuera de la región. Así, de las más de 800 referencias relevantes que aparecen en la base de datos BITRA ${ }^{2}$ a mayo de 2017 -y sin pretender que tal cifra represente la totalidad de los artículos publicados bajo aquella temática, ya que no es posible para ninguna base de datos contener la totalidad de lo producido- más del 73,0\% se encuentra en revistas no hispanoamericanas. Es precisamente sobre este segmento de la producción en ETI de tema hispanoamericano (que suma en conjunto 611 artículos publicados fuera de la región) que se practicó un estudio bibliométrico para delimitar la evolución y el estado de la cuestión de la investigación en traducción sobre Hispanoamérica publicada en revistas no hispanoamericanas, lo que implica estudiar la imagen de la traducción en Hispanoamérica vista desde fuera. Tal estudio comprendió el análisis de la evolución de la producción, los idiomas más utilizados, los países más productivos, las temáticas dominantes, las revistas y autores más prolíficos, los principales centros de publicación y la coautoría. Asimismo, el estudio corresponde a un segundo trabajo sobre el tema; complementa entonces una primera iniciativa (Vargas Gómez 2017) que se ocupó de la producción en ETI publicada en revistas hispanoamericanas. Con esta segunda pieza se pretende pues constituir un panorama razonablemente completo del objeto de estudio.

En cuanto al objeto de estudio, Hispanoamérica ha sido tema de importantes iniciativas de investigación en traducción. Tales esfuerzos, de naturaleza principalmente crítica o historiográfica, se han centrado sobre todo en los productos de tal actividad, en su función o en sus productores ${ }^{3}$. No obstante y a pesar de la cantidad de artículos generados, de su variedad temática y de la diversidad de revistas en las que se han publicado, no se han efectuado estudios que tengan como foco de atención la propia investigación en ETI de tema hispanoamericano. Desde un punto de vista informétrico, su desarrollo histórico, aspectos característicos y situación actual resultan prácticamente desconocidos. En términos disciplinares, este tipo de vacíos ha dado pie durante el último par de décadas (Rovira-Esteva, Orero Clavero et al. 2015) a una serie de estudios enfocados en caracterizar la actividad investigativa disciplinar y una de cuyas vertientes se centra en la producción propia de regiones o colectivos puntuales ${ }^{4}$. Sin embargo, la región hispanoamericana ha quedado al margen de tales iniciativas casi por completo y la investigación en traducción sobre Hispanoamérica publicada fuera de la región no ha sido objeto de estudio, ni por sí sola ni en combinación con otro tipo de producción.

\section{El estudio}

El estudio se realizó a partir de una recopilación de referencias bibliográficas a todos los artículos en ETI sobre Hispanoamérica publicados en revistas no hispanoamericanas 
que fue posible hallar -sin limitación de autores o periodos-. Las únicas restricciones fueron la temática (necesariamente hispanoamericana) y la filiación de las revistas (obligatoriamente no hispanoamericana) en que se publicaron los artículos. A cada entrada del corpus se le asignó información concerniente a un conjunto de indicadores descriptivos medibles: tema, autor, año, lugar de publicación, idioma y filiación académica de los autores, entre otros.

La información se extrajo de BITRA $^{5}$ y se utilizó para conformar una base de datos específica que facilitó el procesamiento de los datos. El corpus resultante -611 entradas, correspondientes a los artículos publicados por 532 autores en 193 revistas entre 1932 y 2016 - se analizó bibliométricamente (Grbić y Pöllabauer 2008c; Li 2015; Martínez-Gómez 2015). Tal análisis permitió elaborar una serie de descripciones diacrónicas y sincrónicas del corpus estudiado, que permitieron a su vez derivar un conjunto de interpretaciones y conclusiones oportunas.

\section{La producción}

Se ha acotado el volumen de producción en dos sentidos: primero, en términos comparativos con respecto a la producción en ETI de tema hispanoamericano publicada dentro y fuera de Hispanoamérica y, segundo, únicamente en lo concerniente a lo publicado sobre el tema en revistas externas a la región.

\subsection{La producción dentro y fuera de Hispanoamérica}

La suma de todas las referencias registradas en BITRA a artículos de revista de tema hispanoamericano -incluidos los publicados dentro y fuera de Hispanoaméricaalcanza los 835 documentos a mayo de 2017. Según su lugar de publicación, 611 (el $73,2 \%)$ se publicaron fuera del territorio hispanoamericano, mientras que los 224 restantes (el 26,8\%) aparecieron en revistas hispanoamericanas. Las diferencias en la evolución y distribución de la producción sobre el tema durante los últimos 90 años en cada región se aprecian en el siguiente gráfico.

\section{GRÁFICO 1}

Evolución por decenio de los artículos de tema hispanoamericano publicados dentro y fuera de Hispanoamérica entre 1926 y 2015

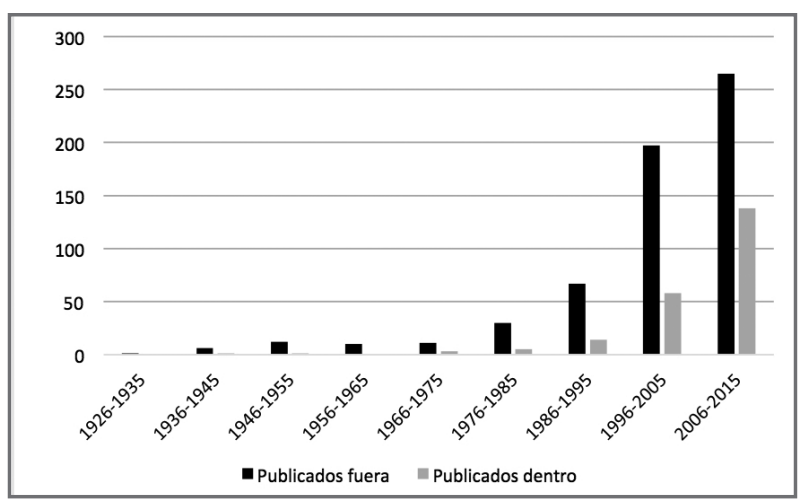

Fuente: BITRA, mayo de 2017 
Tanto las cifras globales como las comparativas demuestran que las publicaciones foráneas han sido el principal espacio de publicación y discusión de la investigación en ETI de tema hispanoamericano. Esta afirmación se sustenta al menos en dos hechos: el primero, la evidente primacía en términos numéricos de las revistas no hispanoamericanas en cuanto al volumen de trabajos sobre el tema. Tal situación parece indicar cierta preferencia de los autores -incluidos los de filiación hispanoamericana- por los medios no hispanoamericanos, así como cierta apertura de tales medios hacia aquel tipo de trabajos. Dicha situación podría explicarse, al menos en parte, a partir de la hegemonía y atractivo que históricamente han ejercido sobre los investigadores ciertas regiones (no hispanoamericanas) en términos científicos, culturales y académicos. A ello puede sumarse, más recientemente, el empuje de determinadas políticas editoriales y académico-institucionales que han pretendido encauzar los flujos de publicación en direcciones muy concretas. El segundo, las fechas de publicación: las revistas no hispanoamericanas inician la publicación de trabajos de tema hispanoamericano de forma más sistemática antes que sus contrapartes en Hispanoamérica -entre 1986 y 1996 en el primer caso y 10 años más tarde en el segundo caso-.

El gráfico sugiere también un aumento del interés por Hispanoamérica como tema de investigación en ETI tanto dentro como fuera del área, en línea con la espectacular expansión de todo lo relacionado con los ETI, especialmente a partir de los años ochenta. Sin embargo, revela que el ámbito de publicación no hispanoamericano se adelanta también en tal sentido: Hispanoamérica comienza a llamar la atención de las publicaciones externas más o menos una década antes de que las revistas hispanoamericanas inicien la publicación de artículos centrados en su propia realidad de una manera más consistente. Este hecho bien podría relacionarse con la mayor longevidad y especialización de las revistas no hispanoamericanas. Por otro lado, parece evidente que el rezago en el tiempo de las revistas hispanoamericanas se correlaciona con el desarrollo tardío de la disciplina en la región latinoamericana en general, en comparación con el desarrollo de los ETI en los ámbitos europeo, canadiense y estadounidense -dentro de los cuales, como se verá más adelante, se han publicado la mayoría de los artículos examinados-.

A pesar de la recién expuesta preeminencia histórica de las revistas no hispanoamericanas, los valores comparativos por decenio dejan entrever que el porcentaje que alcanza lo publicado dentro de Hispanoamérica crece constantemente con respecto a lo que se publica fuera. Así por ejemplo, si entre 1976 y 1985 la relación de lo que se publicó fuera y dentro es de 6 a 1, entre 1986 y 1995 pasa a ser de aproximadamente 5 a 1, para llegar a ser de 3,4 a 1 entre 1996 y 2005 y, finalmente, de 1,9 a 1 durante la última década. Es de suponer que los recientes avances en ETI dentro del área hispanoamericana -en materia de planes de estudio, formación de investigadores, redes de colaboración y producción editorial- han ido confiriendo a la región un mayor protagonismo en la investigación sobre Hispanoamérica.

\subsection{Evolución y situación real}

En el gráfico 2 se muestra la distribución y evolución por decenio durante los últimos 90 años de los 611 artículos referidos en el corpus de trabajo. Resulta evidente la desigualdad a lo largo del periodo. 
GRÁFICO 2

Evolución de la producción publicada entre 1926 y 2015

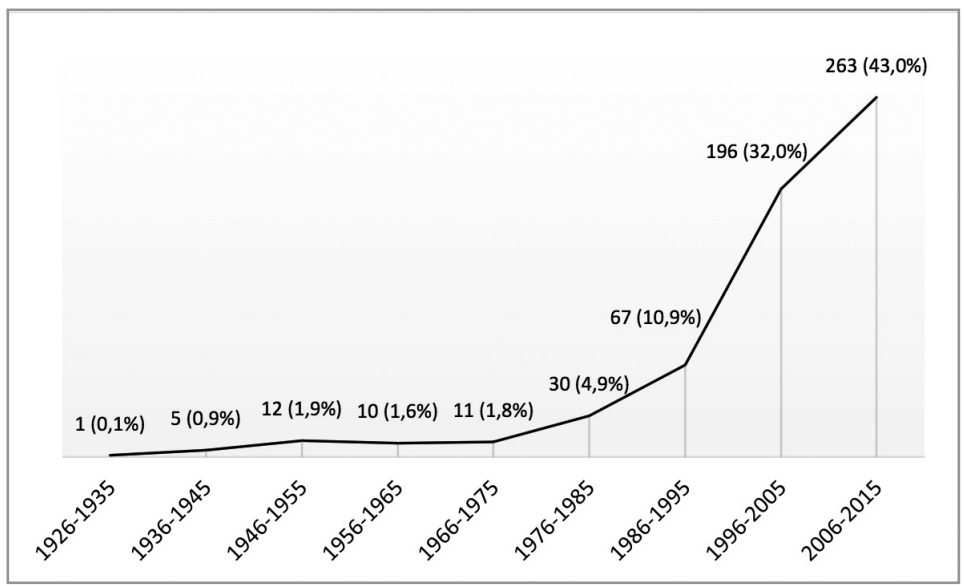

Fuente: BITRA, mayo de 2017

La disposición de las cifras en el gráfico sugiere la existencia de tres periodos: una primera y más extensa etapa de medio siglo (hasta 1975) y muy baja productividad (apenas supera el 6,5\% del total); un segundo periodo (1976-1995) durante el que se dobla en solo dos décadas el total de la producción de los primeros 50 años $(15,9 \%$ del total); y una tercera fase, que inicia a mediados de los años noventa, en la que se publican aproximadamente tres de cada cuatro de los artículos existentes (el 75,1\%; porcentaje que aumenta al 77,5\% si se incluye la producción de 2016).

Esta evolución indicaría un aumento sostenido del interés de las revistas no hispanoamericanas en Hispanoamérica como tema principalmente a partir de mediados de los años noventa. Dado que el incremento del interés parece dar un salto significativo durante el decenio 1996-2005, puede especularse que la publicación de las investigaciones sobre Hispanoamérica en revistas externas se habría beneficiado del auge del enfoque historiográfico en ETI acaecido durante aquel mismo periodo ${ }^{6}$; especialmente si consideramos que esta temática a menudo llama la atención de los investigadores en ETI sobre la región (véase $\$ 5$. Las áreas temáticas).

Por otra parte, el tímido aumento de la productividad que se percibe incluso desde 1976 parece indicar cierto paralelismo entre el desarrollo histórico disciplinar y el espacio dedicado a los trabajos en ETI de tema hispanoamericano en las revistas externas. Dicho esto, llama la atención que más del 77,0\% de lo publicado se concentre en las últimas dos décadas, principalmente porque tal cifra se encuentra por encima del porcentaje correspondiente a artículos de revista para el conjunto de la disciplina registrado en BITRA entre 1996 y 2017, que solo alcanza el 68,2\% del total. Este hecho sugiere que para las revistas con filiación no hispanoamericana, la investigación en ETI sobre Hispanoamérica es una actividad en ciernes. Asimismo, dado el crecimiento sostenido durante las últimas décadas, parece lejos de haber alcanzado su techo. 


\section{Los idiomas y los países de publicación}

Como se muestra en el cuadro 1, el inglés es la lengua de publicación más utilizada: prácticamente uno de cada dos artículos en el corpus se publicó en aquella lengua, lo cual resulta consistente con las cifras globales en términos disciplinares (el 53,7\% del total de artículos registrados en BITRA también se ha publicado en inglés).

\section{CUADRO 1}

Artículos por idioma antes y después de 1996

\begin{tabular}{l|r|r|r|r}
\hline \multicolumn{1}{c}{ Idioma } & $\begin{array}{c}\text { Cantidad de } \\
\text { artículos }^{7}\end{array}$ & \multicolumn{1}{c}{$\begin{array}{c}\text { Antes de } \\
1996\end{array}$} & \multicolumn{1}{c}{$\begin{array}{c}\text { A partir de } \\
1996\end{array}$} & $\begin{array}{c}\text { Porcentaje } \\
\text { del total }\end{array}$ \\
\hline Inglés & $288(100 \%)$ & $82(28,4 \%)$ & $206(71,5 \%)$ & $47,1 \%$ \\
\hline Español & $241(100 \%)$ & $40(16,6 \%)$ & $201(83,4 \%)$ & $39,4 \%$ \\
\hline Francés & $45(100 \%)$ & $13(28,8 \%)$ & $32(71,1 \%)$ & $7,3 \%$ \\
\hline Portugués & $24(100 \%)$ & $1(4,1 \%)$ & $23(95,8 \%)$ & $3,9 \%$ \\
\hline Alemán & $6(100 \%)$ & $2(33,3 \%)$ & $4(66,6 \%)$ & $0,9 \%$ \\
\hline Catalán & $4(100 \%)$ & 0 & $4(100 \%)$ & $0,6 \%$ \\
\hline Checo & $2(100 \%)$ & 0 & $2(100 \%)$ & $0,3 \%$ \\
\hline Neerlandés & $2(100 \%)$ & 0 & $2(100 \%)$ & $0,3 \%$ \\
\hline Chino & $1(100 \%)$ & 0 & $1(100 \%)$ & $0,1 \%$ \\
\hline Gallego & $1(100 \%)$ & 0 & $1(100 \%)$ & $0,1 \%$ \\
\hline Italiano & $1(100 \%)$ & 0 & $1(100 \%)$ & $0,1 \%$ \\
\hline Turco & $1(100 \%)$ & 0 & $1(100 \%)$ & $0,1 \%$ \\
\hline Vasco & $1(100 \%)$ & 0 & $1(100 \%)$ & $0,1 \%$ \\
\hline Total & $617(100 \%)$ & $138(22,3 \%)$ & $479(77,6 \%)$ & - \\
\hline
\end{tabular}

Fuente: BITRA, mayo de 2017

El predominio del inglés en nuestro corpus se explicaría a partir de la adopción por parte de la comunidad científica y editorial internacional de la lengua inglesa como vehículo de difusión casi obligatorio, cuyo uso aumentaría las posibilidades de publicación y visibilidad. Por otra parte, el elevado porcentaje que en conjunto alcanzan los artículos publicados en lenguas que no fueran el español -seis de cada diezpodría implicar un alto grado de participación de investigadores con filiación no hispanoamericana interesados en nuestro objeto de estudio.

No resulta sorpresivo -dada la temática y lector tipo del corpus- que el español ocupe el segundo lugar de la lista con una cuota muy elevada. Su posicionamiento resulta no solo casi tan relevante como el del inglés, sino que además estaría ganando terreno: antes de 1996 la relación entre los artículos publicados en inglés y español era de 82 a 40 (aproximadamente el doble) a favor del inglés; luego de 1996 pasa a ser de 206 a 201 respectivamente (prácticamente de igualdad). Los números confirmarían así la relevancia y vigencia actual del español en lo que concierne a los ETI de tema hispanoamericano incluso cuando se publica fuera de Hispanoamérica y, al menos en términos cuantitativos, implicarían un cierto proceso de igualación del peso que tiene la imagen de la traducción en Hispanoamérica que se proyecta desde el interior de la región con la que se proyecta desde el exterior. La situación resulta más relevante aún si se considera que el 39,4\% que ocupa el español en este caso sobrepase por mucho al 15,1\% que alcanza en el total de artículos registrados en BITRA a mayo de 2017. 
La favorable posición del español en este caso, según lo recién descrito, se debería al menos a tres razones. Primero, a la temática tratada que, claro está, apela de manera muy particular a los hispanohablantes, principalmente en Hispanoamérica, pero también en entornos históricamente ligados a la región, como sería el caso de España o de determinados colectivos en los Estados Unidos. Segundo, a una cierta defensa por parte de algunos autores y revistas del español como vehículo de transmisión de conocimientos concernientes a una región hispanohablante y entre cuyos usuarios más interesados el español resulta ser la lengua de uso común. Tercero, y quizá la razón principal, a las amplias posibilidades de publicar en español fuera de Hispanoamérica que ofrece España gracias a su potente y muy consolidada estructura editorial en revistas de ETI (compárese Franco Aixelá 2012).

Al igual que sucediera con las lenguas, la distribución de artículos publicados por país se presenta muy desigual y con un alto grado de concentración (Cuadro 2): el 79,7\% de los artículos bajo estudio se publicaron en tan solo cinco (el 16,1\%) de los 31 países involucrados en su edición.

CUADRO 2

Países con tres o más artículos ${ }^{8}$

\begin{tabular}{lcc}
\hline \multicolumn{1}{c}{ País } & $\begin{array}{c}\text { Cantidad } \\
\text { de artículos }\end{array}$ & $\begin{array}{c}\text { Porcentaje } \\
\text { del total }\end{array}$ \\
\hline Estados Unidos & 165 & $27,0 \%$ \\
\hline España & 158 & $25,8 \%$ \\
\hline Canadá & 66 & $10,8 \%$ \\
\hline Brasil & 57 & $9,3 \%$ \\
\hline Transnacional ${ }^{9}$ & 41 & $6,7 \%$ \\
\hline Reino Unido & 32 & $5,2 \%$ \\
\hline Francia & 17 & $2,7 \%$ \\
\hline Suiza & 12 & $1,9 \%$ \\
\hline Alemania & 7 & $1,1 \%$ \\
\hline Israel & 6 & $0,9 \%$ \\
\hline Países Bajos & 6 & $0,9 \%$ \\
\hline Italia & 4 & $0,6 \%$ \\
\hline Australia & 3 & $0,4 \%$ \\
\hline República Checa & 3 & $0,4 \%$ \\
\hline
\end{tabular}

Fuente: BITRA, mayo de 2017

La cantidad de artículos publicados por los dos primeros países de la lista -que supera el 50,0\% del corpus- así como la marcada diferencia con respecto a las restantes regiones en el cuadro permiten presumir una sólida relación entre el objeto de estudio y los lugares en donde se publican artículos en ETI sobre tal objeto. La cercanía histórica entre Hispanoamérica y los espacios estadounidense y español es por sí sola razón suficiente para que en ambos países se acojan con interés preferente los estudios que lleguen desde fuera. La elevada participación de ambos países en la publicación de los artículos bajo análisis - por lo demás casi equiparada- evidencia el alto grado de interés que existe en ambos espacios por la investigación en ETI de tema hispanoamericano y revela las preferencias geográfico-editoriales de los autores dedicados al tema, ya porque forman parte de dichos espacios o han establecido lazos 
cercanos con ellos, ya por representarles entornos disciplinares ideales, ya por las facilidades editoriales que encuentran con respecto a otros espacios.

\section{Las áreas temáticas}

El análisis del corpus revela una concentración temática en torno a los estudios de caso (centrados en autores), lo literario y, en menor medida, lo histórico. El cuadro 3 presenta la distribución por temas.

\section{CUADRO 3}

\section{Distribución temática}

\begin{tabular}{|c|c|c|}
\hline Tema & $\begin{array}{c}\text { Cantidad } \\
\text { de artículos }{ }^{10}\end{array}$ & $\begin{array}{c}\text { Porcentaje } \\
\text { del total }\end{array}$ \\
\hline Autor-estudio de caso ${ }^{11}$ & 361 & $59,0 \%$ \\
\hline Literatura & 357 & $58,4 \%$ \\
\hline Historia & 145 & $23,7 \%$ \\
\hline Profesión & 58 & $9,4 \%$ \\
\hline Religión & 58 & $9,4 \%$ \\
\hline Política de traducción & 52 & $8,5 \%$ \\
\hline Ideología & 33 & $5,4 \%$ \\
\hline Interpretación & 32 & $5,2 \%$ \\
\hline Colonialismo & 29 & $4,7 \%$ \\
\hline Científico-técnica & 28 & $4,5 \%$ \\
\hline Estudios de género & 22 & $3,6 \%$ \\
\hline Pedagogía & 15 & $2,4 \%$ \\
\hline Bibliografía & 10 & $1,6 \%$ \\
\hline Audiovisual & 9 & $1,4 \%$ \\
\hline Cultura & 8 & $1,3 \%$ \\
\hline Calidad & 7 & $1,1 \%$ \\
\hline Lingüística & 7 & $1,1 \%$ \\
\hline Dialecto & 6 & $0,9 \%$ \\
\hline Deconstrucción & 5 & $0,8 \%$ \\
\hline Equivalencia & 5 & $0,8 \%$ \\
\hline Terminología & 3 & $0,4 \%$ \\
\hline Documentación & 2 & $0,3 \%$ \\
\hline Automática & 1 & $0,1 \%$ \\
\hline Metáfora & 1 & $0,1 \%$ \\
\hline Registro & 1 & $0,1 \%$ \\
\hline
\end{tabular}

Fuente: BITRA, mayo de 2017

La marcadísima tendencia hacia los estudios de caso $(59,0 \%)$, lo literario $(58,4 \%)$ o lo histórico $(23,7 \%)$-que sobrepasa con creces su presencia en el total de artículos registrados en BITRA (21,9\%, 26,1\% y 10,9\% respectivamente)- deja entrever el valor que se le otorga desde ámbitos externos a Hispanoamérica como tema de investigación en ETI. Por otra parte y sin desmerecer en absoluto los esfuerzos realizados desde la ramas literaria e histórica, no dejan de ser preocupantes los porcentajes comparativamente bajos que alcanza la investigación de tema hispanoamericano en 
campos que en la actualidad parecen estar en pleno apogeo en otros entornos (la interpretación, la pedagogía de la traducción, la calidad y la traducción audiovisual, automática o científico-técnica). Evidentemente las revistas no hispanoamericanas no buscan tratar los asuntos hispanoamericanos en combinación con temas de vanguardia o de naturaleza más aplicada en ETI -situación análoga a la que se percibió en general en las revistas hispanoamericanas (Vargas Gómez 2017)-. Tal concentración temática, así como la poca investigación en áreas de más reciente desarrollo, implicaría que en la actualidad existe un alto grado de desconocimiento del desarrollo real de la traducción en Hispanoamérica.

La evolución de las seis áreas temáticas más recurrentes a lo largo de los últimos 70 años se demarca por medio del gráfico 3. Además del acentuado énfasis en lo literario y en los estudios de caso a partir de mediados de los años noventa, destaca el poco crecimiento que han experimentado los temas religioso y profesional, o los relacionados con las políticas de traducción.

GRÁFICO 3

Evolución de las seis áreas temáticas más desarrolladas durante el periodo 1946-2015 ${ }^{12}$

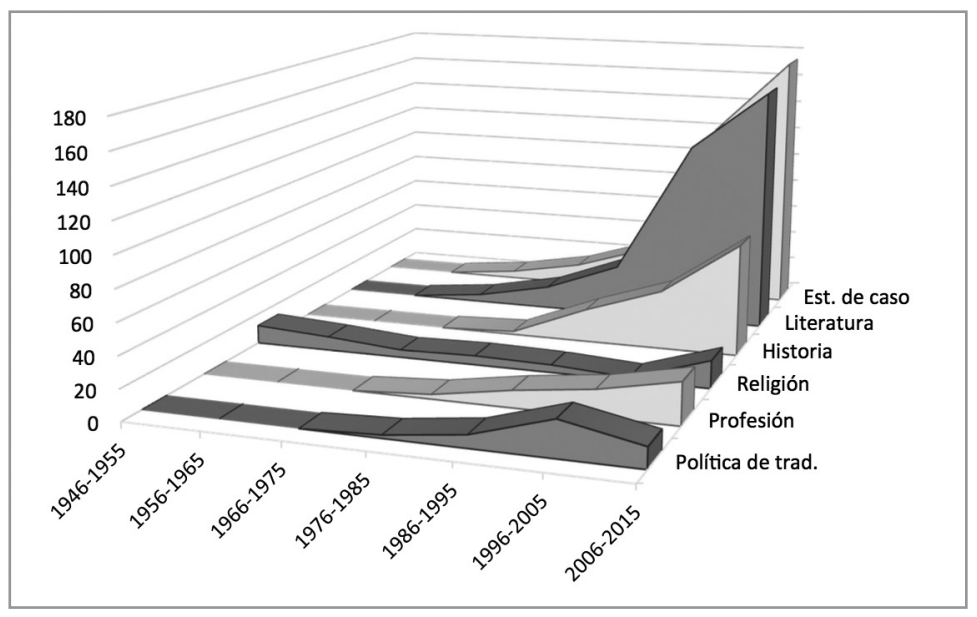

Fuente: BITRA, mayo de 2017

El considerable aumento en la atención que se presta a los temas literarios o a los estudios de caso concuerda en el tiempo con el salto cualitativo y cuantitativo que experimenta el conjunto de la disciplina a partir de 1990. No obstante, en cuanto a la investigación sobre Hispanoamérica que se publica fuera del área, dicha expansión parece haberse limitado al campo literario y a los estudios de caso enfocados en autores específicos y, de manera más tardía y en menor escala, a los asuntos historiográficos. Tal concentración temática genera la impresión de que en Hispanoamérica la actividad traductora se limita casi en su totalidad a los proyectos literarios -al margen de la interpretación, la traducción audiovisual, técnico-científica, legal y médica, o la enseñanza de la traducción, que se practican a diario en la región-.

En el cuadro 4 se presenta el tratamiento dado a cada uno de los países hispanoamericanos. Se muestran además los volúmenes de publicación totales entre 1932 y 2015, así como por decenio durante el periodo 1966-2015. 
CUADRO 4

Artículos de tema hispanoamericano (1932-2015)

\begin{tabular}{|c|c|c|c|c|c|c|}
\hline Tema & $\begin{array}{l}1966- \\
1975\end{array}$ & $\begin{array}{l}1976- \\
1985\end{array}$ & $\begin{array}{c}1986- \\
1995\end{array}$ & $\begin{array}{l}1996- \\
2005\end{array}$ & $\begin{array}{c}2006- \\
2015\end{array}$ & $\begin{array}{c}\text { Total } \\
1932-2015\end{array}$ \\
\hline Argentina & 2 & 2 & 13 & 58 & 79 & $157(25,6 \%)$ \\
\hline México & 2 & 5 & 13 & 19 & 58 & $114(18,6 \%)$ \\
\hline Cuba & 2 & 1 & 4 & 19 & 15 & $42(6,8 \%)$ \\
\hline Chile & 0 & 5 & 4 & 7 & 18 & $34(5,5 \%)$ \\
\hline Perú & 1 & 0 & 3 & 17 & 8 & $34(5,5 \%)$ \\
\hline Colombia & 1 & 1 & 1 & 10 & 12 & $25(4,0 \%)$ \\
\hline Venezuela & 0 & 0 & 0 & 3 & 10 & $13(2,1 \%)$ \\
\hline Ecuador & 0 & 2 & 2 & 0 & 6 & $12(1,9 \%)$ \\
\hline Uruguay & 0 & 0 & 2 & 2 & 5 & $9(1,4 \%)$ \\
\hline Guatemala & 1 & 0 & 1 & 1 & 3 & $7(1,1 \%)$ \\
\hline Puerto Rico & 0 & 0 & 0 & 3 & 3 & $6(0,9 \%)$ \\
\hline Nicaragua & 1 & 0 & 1 & 1 & 1 & $4(0,6 \%)$ \\
\hline Bolivia & 0 & 2 & 0 & 0 & 0 & $3(0,4 \%)$ \\
\hline Costa Rica & 0 & 0 & 0 & 0 & 3 & $3(0,4 \%)$ \\
\hline El Salvador & 0 & 0 & 0 & 0 & 3 & $3(0,4 \%)$ \\
\hline Paraguay & 0 & 1 & 0 & 1 & 1 & $3(0,4 \%)$ \\
\hline Rep. Dominicana & 0 & 0 & 0 & 0 & 3 & $3(0,4 \%)$ \\
\hline Honduras & 0 & 0 & 0 & 0 & 0 & 0 \\
\hline Panamá & 0 & 0 & 0 & 0 & 0 & 0 \\
\hline
\end{tabular}

Fuente: BITRA, mayo de 2017

De entre los países hispanoamericanos, el principal foco de atención de los ETI que se publican fuera de la región lo constituyen Argentina y México. Con una participación conjunta del $44,3 \%$ aventajan por mucho al porcentaje combinado del resto de países $(32,8 \%)$. Es de suponer que su mero tamaño, su devenir histórico, la gran presencia de titulaciones de traducción (al menos en el caso argentino ${ }^{13}$ ) y la internacionalización y canonización de muchas de sus figuras literarias hayan propiciado una labor de investigación mucho más sistemática que la dedicada a los restantes países del área. Cabe apuntar que el 87,9\% de los artículos de tema argentino se combina con temas literarios, de autor o históricos; en el caso de México la cifra equivale al $81,6 \%$ si además se incluye el tema religioso.

A buena distancia se hallan los siguientes cuatro países de la lista (Cuba, Chile, Perú y Colombia). En conjunto, el 71,0\% de los trabajos dedicados a estos cuatro países se combina con el tema «literatura»; si a ello se añaden los trabajos relacionados con asuntos históricos o religiosos o con estudios de caso, la cifra alcanza el 94,3\%. El interés en los restantes países iría de muy bajo (Venezuela, Ecuador, Uruguay, Guatemala, Puerto Rico y Nicaragua) pasando por marginal (Bolivia, Costa Rica, El Salvador, Paraguay y República Dominicana) hasta llegar a nulo (Honduras y Panamá). En promedio, la combinación de temas antes referida (literatura, estudio de caso, historia y religión) para todos estos últimos casos da cuenta del 92,6\% de los artículos relacionados; dicho porcentaje alcanza el $100 \%$ si se cuentan solo los últimos seis países en la tabla que tienen producción relacionada. Tal parece que entre más marginal sea la posición que un país hispanoamericano ocupe como objeto 
de estudio en ETI en revistas no hispanoamericanas, más restringida la visión con que se le aborda y más tradicionales las temáticas de los estudios que se practican con ellos.

La evolución de los volúmenes de producción correspondientes a los ocho primeros países así como las diferencias tan abruptas entre los dos primeros lugares y el resto se visualizan en el gráfico 4 .

GRÁFICO 4

Evolución de los ocho países hispanoamericanos más recurrentes

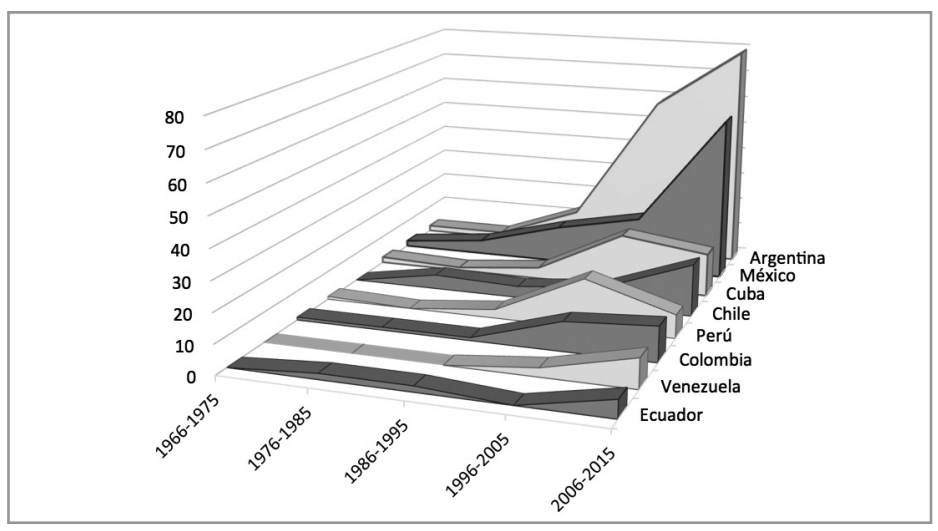

Fuente: BITRA, mayo de 2017

En el gráfico destaca el salto cuantitativo que experimenta el tema «Argentina» entre 1996 y 2005, el crecimiento sostenido que presenta desde entonces y el incremento análogo que se aprecia para el tema «México» una década más tarde. También sobresale el aumento generalizado de casi todos los países durante el último decenio. Supondría ello un incremento en el interés que generan los países de la región, esto, claro, sin negar el notable desequilibrio en favor de los temas «Argentina» $\mathrm{y}$ «México».

\section{Las revistas}

Es principalmente en revistas estadounidenses y españolas en las que se han publicado más estudios en ETI de tema hispanoamericano fuera de Hispanoamérica. Por otro lado, con una única excepción, ninguna revista sobrepasa el 5,0\% del total publicado (Cuadro 5).

Las cifras implican que la producción se encuentra más repartida que la de las revistas hispanoamericanas: basta con recordar que los 611 artículos ahora analizados están repartidos entre 193 revistas, mientras que los 224 publicados en territorio hispanoamericano se distribuyen entre 73 publicaciones. El cuadro revela además que ninguna revista concentra gran cantidad de artículos más allá del 8,7\% publicado en Translation Review -a diferencia de la colombiana Mutatis Mutandis, que acumula el 25,0\% de los artículos en ETI publicados dentro de Hispanoamérica (Vargas Gómez 2017)-. También al contrario de lo que ocurría en Hispanoamérica (donde, hasta donde se conoce, existe una única revista especializada viva), de las 18 revistas más productivas ahora estudiadas 16 se especializan en ETI. Así, la falta de revistas espe- 
CUADRO 5

Las 18 revistas más productivas $(\geq 10)$

\begin{tabular}{|c|c|c|c|c|}
\hline Revista & País & Entidad editorial & Artículos & $\begin{array}{c}\text { Porcentaje } \\
\text { del total }\end{array}$ \\
\hline Translation Review & Estados Unidos & UT Dallas & 53 & $8,6 \%$ \\
\hline Meta & Canadá & Université de Montréal & 28 & $4,5 \%$ \\
\hline$T T R$ & Canadá & $\begin{array}{l}\text { Association canadienne de } \\
\text { traductologie }\end{array}$ & 25 & $4,0 \%$ \\
\hline Cadernos de Tradução & Brasil & $\begin{array}{l}\text { Universidade Federal de } \\
\text { Santa Catarina }\end{array}$ & 21 & $3,4 \%$ \\
\hline Notes on Translation & Estados Unidos & SIL International & 19 & $3,1 \%$ \\
\hline Bible Translator & Transnacional & United Bible Societies & 15 & $2,4 \%$ \\
\hline In-Traduções & Brasil & $\begin{array}{l}\text { Universidade Federal de } \\
\text { Santa Catarina }\end{array}$ & 15 & $2,4 \%$ \\
\hline TRANS & España & Universidad de Málaga & 15 & $2,4 \%$ \\
\hline 1611 & España & $\begin{array}{l}\text { Universitat Autònoma de } \\
\text { Barcelona }\end{array}$ & 14 & $2,2 \%$ \\
\hline Livius & España & Universidad de León & 14 & $2,2 \%$ \\
\hline Vasos comunicantes & España & ACE Traductores & 14 & $2,2 \%$ \\
\hline Babel & Transnacional & $\begin{array}{l}\text { Fédération Internationale } \\
\text { des Traducteurs }\end{array}$ & 13 & $2,1 \%$ \\
\hline Parallèles & Suiza & Université de Genève & 12 & $1,9 \%$ \\
\hline The ATA Chronicle & Estados Unidos & $\begin{array}{l}\text { American Translators } \\
\text { Association }\end{array}$ & 12 & $1,9 \%$ \\
\hline Transfer & España & Universitat de Barcelona & 12 & $1,9 \%$ \\
\hline Hermeneus & España & Universidad de Valladolid & 10 & $1,6 \%$ \\
\hline Istmo & Estados Unidos & Denison University & 10 & $1,6 \%$ \\
\hline Panace@ & España & TREMÉDICA & 10 & $1,6 \%$ \\
\hline
\end{tabular}

Fuente: BITRA, mayo de 2017

cializadas dentro de la región hispanoamericana y la relativa abundancia de ellas en ámbitos externos se contarían entre las razones de que tres cuartas partes de lo que se publica sobre el tema se coloque fuera de Hispanoamérica.

Resulta llamativo que los tres primeros puestos del cuadro estén ocupados por reconocidas revistas en el medio (Translation Review, Meta y TTR, a las que se suma Babel, que aparece en el puesto 12). Tal situación sugiere la existencia de espacios de publicación reales para estudios de tema hispanoamericano entre publicaciones con cierto renombre en el campo.

Como reflejo de lo ocurrido con las regiones de publicación más prolíficas (véase $\$ 4$ ), entre las 18 revistas más productivas destacan las siete publicaciones españolas y las cuatro estadounidenses que, conjuntamente, dan cuenta del 29,9\% de los artículos. Su protagonismo cobra mayor relevancia aún si se considera que de las 193 publicaciones estudiadas, 49 se publican en los Estados Unidos y 50 en España, lo que equivale al $51,3 \%$ de las revistas en que se han publicado artículos de tema hispanoamericano fuera de Hispanoamérica. Sin demérito alguno hacia lo publicado en el restante $48,7 \%$ de las revistas, es esto prueba de la ya mencionada buena acogida que tendría el tema en ambos países. 
Los comités editoriales de las 18 revistas en el cuadro 5 están constituidos por 162 miembros: 66 cuentan con filiación europea, 38 una combinación de canadiense y estadounidense, 16 lusoamericana, 14 hispanoamericana, 13 asiática, seis africana y seis más oceánica ${ }^{14}$. Se desconoce la filiación académica de los tres miembros restantes. El gráfico 5 muestra esta distribución con claridad.

\section{GRÁFICO 5}

Filiación de los comités editoriales de las 18 revistas más productivas

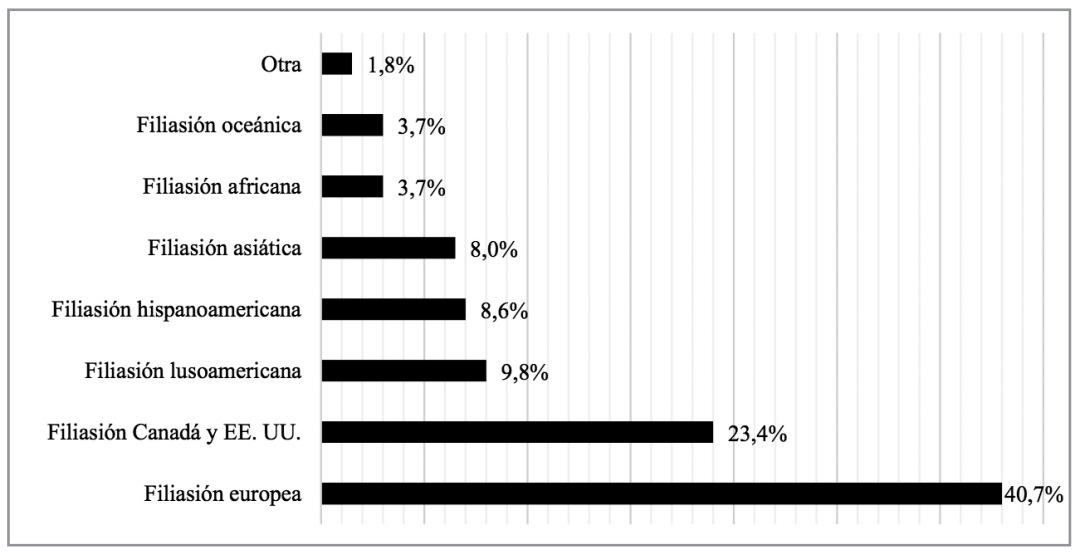

Fuente: Las revistas o sus páginas electrónicas

Los porcentajes alcanzados en cada caso revelan un sistema editorial con un centro dominado (numéricamente hablando) por europeos, seguidos de una profusa participación canadiense-estadounidense y una periferia nutrida de lusoamericanos, hispanoamericanos, asiáticos y, finalmente, aún mucho más alejados del centro, los de filiación africana y oceánica. Aunque este cálculo no incluye los comités editoriales de las 193 revistas estudiadas, debe recordarse que las 18 a partir de las cuales se generó el gráfico son responsables del 51,1\% de los artículos en el corpus de trabajo.

Como se esperaba, la participación hispanoamericana es más bien escasa -caso contrario a lo que ocurría con los comités editoriales de las revistas hispanoamericanas más productivas, entre cuyos miembros el $61,3 \%$ presentaba filiación hispanoamericana (Vargas Gómez 2017)-. El 8,6\% que alcanza es casi igual al 8,0\% asiático y menor que el 9,9\% lusoamericano. La situación pone de manifiesto la exigua participación y visibilidad de los hispanoamericanos en el ámbito editorial internacional de los ETI. Tal configuración no sorprende al considerar que la mayoría de las 18 publicaciones referidas se editan en Europa, Canadá o Estados Unidos. No obstante, los resultados serían indicativos de una escasa interacción por parte de estos tres espacios editoriales en ETI con otros ámbitos o actores, lo cual caracterizaría al sistema en este caso como altamente exclusivo. Si se toma en cuenta que la conformación de tales comités se realiza en buena medida por invitación, la escasa participación de los estudiosos hispanoamericanos en ETI volvería a explicarse a partir del poco interés que despierta en el exterior lo hispanoamericano más allá de lo histórico, cultural o literario. 


\section{Los autores más productivos}

La producción de los 40 autores más prolíficos se consigna a continuación (Cuadro 6), junto con su filiación académica y el número de documentos que han escrito en coautoría.

CuAdro 6

Los 40 autores con mayor producción ${ }^{15}$

\begin{tabular}{|c|c|c|c|}
\hline Nombre & Filiación académica & $\begin{array}{l}\text { Cantidad de } \\
\text { artículos }\end{array}$ & $\begin{array}{c}\% \text { del } \\
\text { total }\end{array}$ \\
\hline Bastin, Georges L. & Université de Montréal (Canadá) & 9 (4 en coautoría) & $1,4 \%$ \\
\hline $\begin{array}{l}\text { Arencibia Rodríguez, } \\
\text { Lourdes Beatriz }\end{array}$ & [Sin institución] Cuba & 6 (1 en coautoría) & $0,9 \%$ \\
\hline Payàs Puigarnau,Gertrudis & Universidad Católica de Temuco (Chile) & 6 (3 en coautoría) & $0,9 \%$ \\
\hline Stratford, Madeleine & Université du Québec (Canadá) & 6 & $0,9 \%$ \\
\hline Waisman, Sergio & $\begin{array}{l}\text { George Washington University (Estados } \\
\text { Unidos) }\end{array}$ & 6 ( 1 en coautoría) & $0,9 \%$ \\
\hline Alonso Araguás, Icíar & Universidad de Salamanca (España) & 5 (3 en coautoría) & $0,8 \%$ \\
\hline Gargatagli Brusa, Ana & Universidad Autónoma de Barcelona (España) & 5 ( 2 en coautoría) & $0,8 \%$ \\
\hline Munday, Jeremy & Univesity of Leeds (Reino Unido) & 5 ( 1 en coautoría) & $0,8 \%$ \\
\hline Castro Ramírez, Nayelli & University of Ottawa (Canadá) & 4 (1 en coautoría) & $0,6 \%$ \\
\hline Larkosh, Christopher & University of Massachusetts (Estados Unidos) & 4 & $0,6 \%$ \\
\hline Montezanti, Miguel Ángel & Universidad Nacional de la Plata (Argentina) & 4 & $0,6 \%$ \\
\hline Valdeón García, Roberto & Universidad de Oviedo (España) & 4 & $0,6 \%$ \\
\hline Alvstad, Cecilia & Universida de Oslo (Noruega) & 3 ( 1 en coautoría) & $0,4 \%$ \\
\hline Arrojo, Rosemary & Binghamton University (Estados Unidos) & 3 & $0,4 \%$ \\
\hline Baigorri Jalón, Jesús & Universidad de Salamanca (España) & 3 ( 3 en coautoría) & $0,4 \%$ \\
\hline Cohen, Jonathan & [Sin institución] Estados Unidos & 3 (1 en coautoría) & $0,4 \%$ \\
\hline Costa, Walter Carlos & $\begin{array}{l}\text { Universidade Federal de Santa Catarina } \\
\text { (Brasil) }\end{array}$ & 3 ( 1 en coautoría) & $0,4 \%$ \\
\hline Fossa, Lydia & University of Arizona (Estados Unidos) & 3 & $0,4 \%$ \\
\hline Guzmán, María Constanza & Universidad de York (Canadá) & 3 ( 1 en coautoría) & $0,4 \%$ \\
\hline Majstorovic, Gorica & Richard Stockton College (Estados Unidos) & 3 & $0,4 \%$ \\
\hline Pagano, Adriana Silvina & Universidade Federal de Minas Gerais (Brasil) & 3 & $0,4 \%$ \\
\hline Pagni, Andrea & Universidad Erlangen-Nuremberg (Alemania) & 3 & $0,4 \%$ \\
\hline Ruíz Casanova, José F. & Universitat Pompeu Fabra (España) & 3 & $0,4 \%$ \\
\hline Sales Salvador, Dora & Universidad Jaume I (España) & 3 & $0,4 \%$ \\
\hline Spoturno, María Laura & Universidad Nacional de La Plata (Argentina) & 3 ( 1 en coautoría) & $0,4 \%$ \\
\hline Vega Cernuda, Miguel Á. & Universidad de Alicante (España) & 3 & $0,4 \%$ \\
\hline Venturini, Santiago & CONICET (Argentina) & 3 & $0,4 \%$ \\
\hline Willson, Patricia & Universidad de Lieja (Bélgica) & 3 & $0,4 \%$ \\
\hline Abreu, Milagros & $\begin{array}{l}\text { Boston University School of Medicine } \\
\text { (Estados Unidos) }\end{array}$ & 2 ( 2 en coautoría) & $0,3 \%$ \\
\hline Albaladejo, Juan Antonio & Universidad de Alicante (España) & 2 & $0,3 \%$ \\
\hline Barretto, Eleonora Frenkel & $\begin{array}{l}\text { Universidade Federal de Santa Catarina } \\
\text { (Brasil) }\end{array}$ & 2 & $0,3 \%$ \\
\hline Bensoussan, Albert & Universidad de Rennes-2 (Francia) & 2 & $0,3 \%$ \\
\hline Bush, Peter & University of East Anglia (Reino Unido) & 2 & $0,3 \%$ \\
\hline
\end{tabular}




\begin{tabular}{lllr} 
Cabrera Ponce, Ileana & $\begin{array}{l}\text { Pontificia Universidad Católica de Chile } \\
\text { (Chile) }\end{array}$ & 2 (1 en coautoría) & $0,3 \%$ \\
\hline $\begin{array}{l}\text { Cowan, Florence H. } \\
\text { Díaz Peralta, Marina }\end{array}$ & $\begin{array}{l}\text { Wycliffe Bible Translators (Internacional) } \\
\text { (Esp.) }\end{array}$ & 2 & $0,3 \%$ \\
\hline $\begin{array}{l}\text { Diffie, Bailey W. } \\
\text { Doorslaer, Luc van }\end{array}$ & City College of New York (Estados Unidos) & 2 (1 en coautoría) & $0,3 \%$ \\
Ellis, Keith & KU Leuven (Bélgica) & 2 (1 en coautoría) & $0,3 \%$ \\
Flores, Glenn & Universidad de Toronto (Canadá) & 2 coautoría) & $0,3 \%$ \\
\hline Total & $\begin{array}{l}\text { Boston University School of Medicine } \\
\text { (Estados Unidos) }\end{array}$ & 2 (2 en coautoría) & $0,3 \%$ \\
\hline
\end{tabular}

Fuente: BITRA, mayo de 2017

El cuadro está dominado por autores con filiación europea (16, de entre los que destacan los nueve españoles) y angloamericana (14, con nueve estadounidenses y cinco canadienses). Los seis autores con filiación hispanoamericana se ven relegados a una tercera posición -muy por el contrario a lo sucedido con las revistas hispanoamericanas: de los 23 autores más prolíficos en aquel caso, 18 contaban con filiación hispanoamericana, aunque, ciertamente, no todas sus publicaciones eran de tema hispanoamericano (Vargas Gómez 2017)-. En esa misma línea, resulta muy significativo que el primer lugar de la tabla esté ocupado por un autor con filiación no hispanoamericana. La baja participación hispanoamericana en este sentido podría deberse a varios factores: un cierto desinterés por parte de los estudiosos hispanoamericanos en ETI por asuntos locales; lo tardío del desarrollo de la disciplina en la región y, en consecuencia, la escasez de investigadores con filiación hispanoamericana; la existencia de mayores trabas editoriales que las que habrían encontrado sus contrapartes angloamericanas o europeas; la menor visibilidad de sus publicaciones; o una combinación de todos ellos. Tal desequilibrio se confirma si se extiende la lista a los 80 autores más prolíficos: 26 (32,5\%) tienen filiación europea, 25 (31,2\%) angloamericana, $11(13,7 \%)$ hispanoamericana, $8(10,0 \%)$ lusoamericana y $10(12,5 \%)$ alguna otra. Cabe mencionar que 19 (23,7\%) de los autores en este grupo de 80 tienen filiación estadounidense y 13 (16,2\%) española, lo cual vuelve a evidenciar el grado de interés que tendrían ambas regiones por el tema hispanoamericano.

\section{La autoría en colaboración}

De los 611 artículos estudiados poco más de 11 de cada 100 se publicaron en coautoría. Tras un extenso periodo de coproducción prácticamente nula (1926-1975), la publicación en coautoría ha tendido a aumentar decenio tras decenio a partir de mediados de los años setenta (Cuadro 7), aunque el cambio más significativo se experimenta a mitad de la década de 1990.

Al comparar la segunda y cuarta columnas, se observa que a partir de 1976 el incremento en la producción en coautoría ha resultado ser prácticamente proporcional al aumento que experimenta el total de artículos publicados en cada década -con una relación aproximada de un artículo en coautoría por cada 10 del total publicado-. Tal situación cambia durante los últimos 10 años (2006-2015), cuando la proporción pasa a ser aproximadamente de 1,33 documentos escritos en colaboración por cada 10 que se cuentan para el total de artículos publicados. 
CUADRO 7

Artículos en colaboración y autores por decenio

\begin{tabular}{lcccc}
\hline \multirow{2}{*}{ Decenio } & \multicolumn{3}{c}{ Cantidad de artículos } & Cantidad de \\
\cline { 2 - 4 } & $\begin{array}{c}\text { Total } \\
\text { artículos }\end{array}$ & 1 autor & $\begin{array}{c}\text { 2 o más } \\
\text { autores }\end{array}$ & \begin{tabular}{c} 
autores \\
\hline $1926-1935$
\end{tabular} \\
1 & 1 & 1 & 0 & 1 \\
\hline $1936-1945$ & 6 & 5 & 1 & 7 \\
\hline $1946-1955$ & 12 & 12 & 0 & 12 \\
\hline $1956-1965$ & 10 & 9 & 1 & 11 \\
\hline $1966-1975$ & 11 & 10 & 1 & 12 \\
\hline $1976-1985$ & 30 & 27 & 3 & 33 \\
\hline $1986-1995$ & 67 & 61 & 6 & 73 \\
\hline $1996-2005$ & 196 & 176 & 20 & 217 \\
\hline $2006-2015$ & 263 & 228 & 35 & 306 \\
\hline
\end{tabular}

Fuente: BITRA, mayo de 2017

Otros incrementos que se perciben durante el decenio 2006-2015 se relacionan con los índices de colaboración en términos institucionales y regionales (Cuadro 8). El cambio parece gestarse ya durante los dos decenios anteriores (1986-1995 y 1996 2005), antes de los cuales la coautoría es escasa o nula. El volumen de producción en coautoría intrainstitucional pasa de cuatro artículos entre 1986 y 1995 a 19 entre 2006 y 2015, y de 0 a 14 en el caso de la coautoría interinstitucional durante el mismo periodo. En términos de colaboración nacional, la producción se multiplica por un factor de seis al final de las tres últimas décadas y la de tipo internacional, que sumaba apenas un trabajo tres décadas atrás, alcanza los 11 documentos durante el periodo 2006-2015.

CUADRO 8

Artículos en coautoría para el periodo 1946-2015

\begin{tabular}{|c|c|c|c|c|}
\hline \multirow[t]{2}{*}{ Decenio } & \multicolumn{2}{|c|}{$\begin{array}{c}\text { Cantidad de artículos } \\
\text { en colaboración... }\end{array}$} & \multicolumn{2}{|c|}{$\begin{array}{c}\text { Cantidad de artículos } \\
\text { en colaboración... }\end{array}$} \\
\hline & intrainst. & interinst. & nacional & internacional \\
\hline 1946-1955 & 0 & 0 & 0 & 0 \\
\hline 1956-1965 & 0 & 0 & 1 & 0 \\
\hline 1966-1975 & 1 & 0 & 1 & 0 \\
\hline 1976-1985 & 0 & 2 & 3 & 0 \\
\hline 1986-1995 & 4 & 0 & 4 & 1 \\
\hline 1996-2005 & 7 & 5 & 12 & 5 \\
\hline 2006-2015 & 19 & 14 & 25 & 11 \\
\hline - & $31(59,6 \%)$ & $21(40,3 \%)$ & $47(73,4 \%)$ & $17(26,5 \%)$ \\
\hline Total & \multicolumn{2}{|c|}{52 (100\%) } & \multicolumn{2}{|c|}{$64(100 \%)$} \\
\hline
\end{tabular}

Fuente: BITRA, mayo de 2017

Destaca también el hecho de que, del total de artículos en coautoría, más del $40,0 \%$ (dos de cada cuatro) supuso colaboración entre distintas instituciones y por encima del $26,0 \%$ (uno de cada cuatro) entre distintos países o regiones. Tales valores 
superan los delimitados para las revistas hispanoamericanas $-32,1 \%$ y $18,3 \%$ respectivamente (Vargas Gómez 2017)-. Las diferencias porcentuales a favor de la interinstitucionalidad y de la internacionalización de la autoría se deberían al incremento y longevidad de las redes de colaboración, producto a su vez del desarrollo más temprano de los ETI en las regiones europea y angloamericana. Por otra parte, los 21 artículos publicados en colaboración interinstitucional y los 17 de tipo internacional representan respectivamente tan solo un 3,4\% y 2,8\% del corpus analizado. Desde tal perspectiva y a pesar del incremento comentado, resulta claro que el trabajo en colaboración no ha sido una de las principales preocupaciones de los ETI de tema hispanoamericano publicados fuera de Hispanoamérica.

Los artículos en coautoría en los que intervienen autores con filiación hispanoamericana suman un total de 23 documentos. En 11 de ellos colaboraron solamente autores con filiación hispanoamericana; los restantes 12 se publicaron en conjunto con investigadores no hispanoamericanos, siendo lo más común (siete artículos) la coautoría junto con colaboradores de filiación europea (Cuadro 9).

CUADRO 9

Artículos en coautoría con colaboración hispanoamericana

\begin{tabular}{lc}
\hline $\begin{array}{l}\text { Artículos en colaboración } \\
\text { entre autores... }\end{array}$ & Artículos \\
\hline hispanoamericanos y europeos & 7 \\
hispanoamericanos y angloamericanos & 3 \\
hispanoamericanos y lusoamericanos & 1 \\
hispanoamericanos y asiáticos & 1 \\
solo hispanoamericanos & 11 \\
\hline Total & 23 \\
\hline
\end{tabular}

Fuente: BITRA, mayo de 2017

Descontados los 11 artículos escritos de forma exclusiva entre hispanoamericanos, parece posible plantear que las afinidades históricas y lingüísticas explicarían que el volumen de publicación en coautoría entre afiliados hispanoamericanos y europeos sobrepase al resto: de los siete artículos escritos en coautoría entre hispanoamericanos y europeos, seis se publicaron en revistas españolas y en español. Si por una parte se podría considerar que la cercanía entre los ámbitos angloamericano e hispanoamericano, por ejemplo, es mayor a la que podría existir entre este último espacio y Europa, por otra parte el factor España parece ser decisivo en este caso a la hora de desarrollar investigaciones en ETI sobre Hispanoamérica en colaboración.

Al interpretar la alta tasa de coautoría entre hispanoamericanos y no hispanoamericanos en general (12 de 23 documentos) deben considerarse las fechas de publicación: ocho de los 11 artículos en los que solo intervienen hispanoamericanos se publicaron a partir de 2012 (los restantes tres surgieron en 1990, todos en el volumen 35:3 de la revista Meta, dedicado a «La traduction dans le monde hispanolusophone»). Por su parte, la distribución en el tiempo de los 12 artículos escritos en coautoría entre hispanoamericanos y no hispanoamericanos resulta mucho más uniforme: tres durante los noventa, cuatro entre 2002 y 2008, y cinco a partir de 2011, todos publicados en revistas o números diferentes. Las respectivas cuotas de participación 
implicarían que, hasta hace poco, el trabajo en colaboración entre hispanoamericanos habría sido muy escaso, al menos el publicado fuera de Hispanoamérica. El tardío desarrollo de los ETI en la región, la consecuente falta de investigadores locales y las casi inexistentes redes internas de colaboración explicarían tal situación. No obstante, el creciente número de artículos en coautoría de manufactura hispanoamericana durante los últimos seis años en ámbitos editoriales no hispanoamericanos sugiere un posible aumento en la cantidad de investigadores con filiación hispanoamericana durante los últimos años y el reciente establecimiento de redes de colaboración regionales.

\section{Conclusiones}

Para comenzar, debe indicarse que, al menos en términos cuantitativos, las revistas no hispanoamericanas constituyen el principal medio de publicación de artículos en ETI sobre Hispanoamérica (con aproximadamente tres de cada cuatro de los más de 800 artículos registrados en BITRA de tema hispanoamericano). Un más amplio y temprano desarrollo de la disciplina fuera de Hispanoamérica, así como la mayor longevidad, notoriedad y grado de especialización de las revistas no hispanoamericanas con respecto a las hispanoamericanas habrían incidido en la visible brecha productiva y temporal (la publicación de artículos relacionados con el tema en las revistas hispanoamericanas comienza a ser notoria aproximadamente una década después que en las revistas externas).

La producción publicada fuera de Hispanoamérica ha evolucionado en paralelo a la disciplina en general: luego de un extenso periodo de escasa productividad, se percibe un primer aunque tímido incremento en los volúmenes de producción ya desde mediados de los años setenta. No obstante, el verdadero cambio toma lugar durante los últimos 20 años, periodo en que se concentra más del 75,0\% de lo publicado a la fecha. Todo ello sugiere que se está ante una actividad todavía en ebullición, cuyos volúmenes de publicación aún no habrían alcanzado su techo.

Sin restar importancia al posicionamiento del inglés como lengua principal de publicación (288 artículos, de los cuales el 71,5\% se publica a partir de 1996), los datos posicionan al español como un vehículo relevante y muy vigente entre las revistas no hispanoamericanas cuando se trata de investigaciones sobre Hispanoamérica (241 documentos, el 83,4\% de los cuales se publicó en los últimos 20 años). Tal comportamiento revela no solo la existencia de una estructura editorial (mayoritariamente española) que posibilita la publicación en español fuera de Hispanoamérica, sino que además insinúa un aumento durante la última década y media del número de investigadores hispanoparlantes que se ocupan del tema.

La producción en ETI de tema hispanoamericano que se publica en revistas fuera de Hispanoamérica se caracteriza además por ser una actividad altamente concentrada en términos geográficos: el 52,9\% se publicó en suelo estadounidense (27,0\%) y español (25,9\%). Tal situación pone de relieve además la correlación existente a un nivel más general entre los flujos o políticas de publicación en entornos editoriales concretos y la investigación de temas específicos.

Los también elevados índices de concentración temática en asuntos literarios, estudios de caso y aspectos históricos, así como la escasez de trabajos dedicados a áreas de más reciente desarrollo en ETI definen a la producción sobre Hispanoamérica 
que se publica en revistas ajenas a la región y a las mismas revistas como un espacio en el que predomina una visión bastante tradicional de los ETI en relación con Hispanoamérica. Tal aproximación resultaría insuficiente para abordar las complejidades del entorno traductor hispanoamericano -más allá de lo literario, individual o histórico- y a la vez deja ver el valor limitado que se le ha conferido a la región como objeto de estudio desde ámbitos de publicación externos. Al mismo tiempo, pone de manifiesto la consecuente existencia de lagunas de conocimiento sobre la actividad traductora hispanoamericana (su diversidad, evolución, estado actual, etc.). Cabe preguntarse si una de las causas de tal concentración temática radica en una cierta tendencia del ámbito externo a valorar a la región hispanoamericana casi de manera exclusiva a partir de su producción cultural (sobre todo la de carácter literario) o de su devenir histórico, a la vez que como un espacio que se encuentra rezagado en términos científicos, técnicos, industriales, profesionales e incluso pedagógicos. Por otra parte, habría que considerar también el peso que sobre la selección de temas por investigar pudo haber tenido la relación estrecha que han sostenido ciertos ámbitos de los ETI con las Humanidades, en especial el de los estudios literarios y la historia, campos desde los cuales han surgido no pocos investigadores en ETI.

En tanto sistema editorial y en lo que respecta a la publicación de artículos en ETI sobre Hispanoamérica, las 193 revistas estudiadas presentan al menos tres rasgos característicos. El primero, la dispersión de la producción: ninguna concentra documentos con respecto a las demás (un $8,7 \%$ del total la que más). El segundo, la existencia de un centro muy restringido y dominante: el 52,9\% son estadounidenses o españolas. Contrasta entonces la alta dispersión de la producción entre las revistas con la gran concentración de las revistas en términos geográficos. El panorama resulta aún más restringido al observar los comités editoriales de las 18 revistas más productivas: más del $60,0 \%$ de sus miembros tienen filiación europea, canadiense o estadounidense. Tal situación implica una muy baja cuota de participación e interacción de los estudiosos hispanoamericanos en ETI con respecto a los espacios editoriales no hispanoamericanos en los que se publica sobre la región. El tercero, la especialización: 16 de las 18 revistas más productivas son publicaciones especializadas en ETI. Esta particularidad -opuesta a la de sus contrapartes hispanoamericanas (Vargas Gómez 2017)- podría ser uno de los motivos por los cuales el 75,0\% de los artículos en ETI sobre Hispanoamérica registrados en BITRA se ha publicado fuera de suelo hispanoamericano.

Entre los autores más prolíficos sobresale la amplia participación de aquellos con filiación europea, estadounidense o canadiense (75,0\%), así como la escasa presencia de autores con filiación hispanoamericana (15,0\%) -debido, muy probablemente, al tardío desarrollo de los ETI en Hispanoamérica y a la consecuente escasez de investigadores que aborden el tema bajo análisis o cualquier otro tema dentro de los ETI-. La cuota alcanzada por los autores estadounidenses y españoles (el 40,0\% de los 80 autores con dos o más artículos) revela el marcado interés que habría en ambos espacios -en los que se publicó más del 50,0\% de los artículos estudiados y se editan 99 de las 193 revistas involucradas- por la investigación en ETI de tema hispanoamericano.

En lo concerniente a la actividad en coautoría, puede afirmarse lo siguiente: primero, el trabajo en colaboración no parece haber despertado un interés particular entre los autores involucrados (representa apenas el 11,1\% de lo publicado, cifra por debajo del 14,3\% calculado para el conjunto de la disciplina). Segundo, su cuota de 
participación con respecto al total del corpus no presenta una evolución diacrónica significativa hasta hace 10 años, cuando comienza a notarse un ligero incremento en los índices. Tercero, los cambios que se observan en cuanto a los valores absolutos (incremento de la cantidad de artículos publicados década tras década) resultan ser proporcionales a los correspondientes aumentos en el total de la producción sobre el tema. En otras palabras, tal parece que hay más interesados en publicar en coautoría sobre el tema a medida que hay más interesados en publicar sobre el tema en general.

Antes de terminar debe insistirse en que los resultados del análisis practicado y los planteamientos que de ellos se derivan ofrecen una visión por el momento parcial del objeto de estudio y hacen referencia únicamente a los datos estudiados. Al respecto debe recordarse, una vez más, que no se ha pretendido en ningún momento que tales datos den cuenta de todo lo publicado sobre el tema, ya que, a pesar de las 70000 referencias incluidas en BITRA, resulta materialmente imposible para cualquier base de datos contener todo lo publicado a la fecha. Así, las conclusiones recién planteadas aluden de manera exclusiva al segmento del objeto de estudio contenido en BITRA. Adicionalmente y como ya se ha advertido, la investigación realizada corresponde al segundo de un conjunto de trabajos cuyo fin último es la elaboración de un panorama lo más completo posible de la investigación en ETI en y sobre Hispanoamérica desde una perspectiva bibliométrica. Al estudio anterior y al presente todavía debe complementarles al menos un tercero, que abarque la producción bibliográfica que esté más allá de los artículos de revista (libros, capítulos, tesis, monografías, memorias de congresos). No está de más volver a señalar -como se hiciera en el estudio previo- que lo escaso e incipiente de la producción estudiada obliga a ser precavidos y a quedar a la espera de desarrollos posteriores a partir de los cuales confirmar o desmentir los comportamientos recién demarcados.

\section{NOTAS}

* Este artículo se enmarca dentro del proyecto de investigación «El desarrollo de los Estudios de Traducción en y sobre Hispanoamérica: un estudio bibliométrico», aprobado y financiado por la Escuela de Literatura y Ciencias del Lenguaje de la Universidad Nacional de Costa Rica, y se realiza en colaboración con el proyecto BITRA, de la Universidad de Alicante, España, bajo la dirección de Javier Franco Aixelá.

1. Entiéndase por Hispanoamérica en este contexto los países del continente americano entre cuyas lenguas oficiales y más extendidas se encuentre el español: Argentina, Bolivia, Chile, Colombia, Costa Rica, Cuba, Ecuador, El Salvador, Guatemala, Honduras, México, Nicaragua, Panamá, Paraguay, Perú, Puerto Rico, República Dominicana, Uruguay y Venezuela.

2. Franco Aixelá, Javier (Actualizado el 1 de abril de 2019): Bibliografía de Interpretación y Traducción (BITRA). Alicante: Universidad d'Alicante. Consultado el 23 de mayo de 2019, <http:// dti.ua.es/es/bitra/introduccion.html>.

3. Compárese con los trabajos de Georges Bastin (1996, 1998, 2003, 2004, 2007, 2008, 2009, 2010), de Bastin y Castrillón (2004), de Bastin y Díaz (2004), de Bastin y Echeverri (2004), de Bastin, Echeverri et al. (2004), de Bastin e Iturriza (2008), de Bastin, Navarro et al. (2010), del grupo HISTRAD de la Universidad de Alicante (Albaladejo Martínez 2008; Gapper Morrow 2008; García Albero 2008; Rodríguez Chávez 2002/2003; Valero Cuadra 2008; Vargas Gómez 2009, 2010; Vega Cernuda 2008a, 2008b), del grupo Alfaqueque de la Universidad de Salamanca (Alonso y Baigorri 2004, 2007; Alonso, Baigorri et al. 2008; Alonso, Páez et al. 2015; Grupo Alfaqueque 2010; Payás Puigarnau y Zavala 2012), de Lafarga y Pegenaute (2012a, 2012b, 2012c, 2013), de Arencibia Rodríguez y Hernández Valdés (2009), de Sanz, Morejón et al. (2014) y, finalmente, de Arencibia Rodríguez (1997, 1998a, 1998b, 2002, 2003, 2005, 2008a, 2008b, 2009a, 2009b, 2010).

4. Véanse, por ejemplo, los trabajos sobre la interpretación en entornos germanohablantes de Grbić (2008) y de Grbić y Pöllabauer (2008a, 2008b); los estudios centrados en el contexto chino de Li 
(2015), Tang (2010), Wang (2016), Wang y Mu (2009) y Xu y Pekelis (2015); las publicaciones de Franco Aixelá (2012) y de Rovira-Esteva y Orero Clavero (2011 y 2012) enfocadas en el ámbito español; la investigación de Franco Aixelá y Rovira-Esteva (2019) sobre los ETI en países hispanohablantes; y el trabajo de Vargas Gómez (2017) acerca de la producción en ETI en revistas con filiación hispanoamericana (antecedente más próximo al estudio realizado a la vez que trabajo complementario).

5. BITRA (2001-2018) es una base de datos multilingüe de acceso libre, creada y coordinada por Javier Franco Aixelá, profesor de la Universidad de Alicante. A la fecha cuenta con más de 70000 entradas, lo cual la convierte en el repositorio de referencias bibliográficas en traducción más amplio que existe en la actualidad (con más del doble de referencias, por ejemplo, que el otro referente en el campo: la base de datos Translation Studies Bibliography, de John Benjamins).

6. Al respecto, Vega Cernuda y Pulido (2013: 18-19) apuntan que ya desde principios de los años noventa se percibía un cambio significativo en el desarrollo y aplicación del enfoque historiográfico en ETI.

7. La suma es mayor al total de documentos ya que algunos artículos se publicaron en más de un idioma.

8. La lista la completan las siguientes regiones: con dos artículos, Austria, Dinamarca, Escocia y Rumanía; con un artículo, Bélgica, China, Europa, Grecia, Hungría, India, Marruecos, Polonia, Portugal, Suecia, Taiwán y Turquía. No fue posible dar con el país de edición del 2,2\% del corpus (13 artículos).

9. En esta categoría se incluyen los artículos publicados en revistas cuya entidad editorial tiene presencia en más de un único espacio geopolítico o representa a múltiples espacios a la vez; por lo tanto, no pueden clasificarse como pertenecientes o afincadas en un país o región específicas.

10. La suma es mayor al total de documentos estudiados ya que casi todos los artículos se clasifican en más de una categoría al abordar varios temas simultáneamente.

11. Al combinar los estudios de caso con las siguientes 10 áreas temático-disciplinares más recurrentes se obtienen las siguientes cifras: 289 artículos para la combinación «estudio de caso y literatura», 61 para «estudio de caso e historia», 24 para «estudios de caso y profesión», 14 para "estudio de caso y religión», siete para «estudio de caso y política de traducción», 27 para «estudio de caso e ideología», seis para «estudio de caso e interpretación», 12 para "estudio de caso y colonialismo», seis para "estudio de caso y científico-técnica» y 18 para «estudio de caso y estudios de género». La combinación con las restantes áreas temático-disciplinares no supera en ningún caso los cuatro documentos.

12. No se incluyeron los temas relacionados con regiones o países en el gráfico ya que, a diferencia de los seis temas representados, no se les considera áreas temático-disciplinares.

13. A propósito de dicha presencia y según los datos suministrados por Franco Aixelá y Rovira-Esteva (2019), en la actualidad se encuentran activos en Argentina al menos 40 programas de estudio en traducción conducentes a una titulación, cifra que sobrepasa por mucho a las 15 titulaciones que se ofrecen en Chile y a las 11 ofertadas en México. En la misma línea, los investigadores dan cuenta de por lo menos 24 instituciones argentinas en donde se imparte la traducción como carrera universitaria, en las modalidades de bachillerato (BA), maestría (MA) o doctorado (PhD). Tales cifras vuelven a superar las del resto de la región (ocho instituciones en México y siete en Chile, segundo y tercer lugar respectivamente) e incluso las de espacios con cierta tradición en ETI como Canadá, en donde se cuenta con aproximadamente una docena de instituciones universitarias en las que se imparten diferentes grados (BA, MA o $\mathrm{PhD}$ ) en traducción.

14. Al hacer el cálculo no se han tomado en cuenta las extintas revistas Livius ni Notes on Translation, ya que no fue posible localizar los datos correspondientes.

15. El cálculo de la cantidad de artículos se realizó en cada caso por medio de un conteo completo.

\section{REFERENCIAS BIBLIOGRÁFICAS}

Albaladejo Martínez, Juan Antonio (2008): La traducción del espacio novelesco de Fernando Contreras Castro y su transferencia a la realidad alemana. Letras. 43:177-192.

Alonso Araguás, Icíar y Baigorri JALón, Jesús (2004): Iconography of Interpreters in the Conquest of the Americas. TTR. 17(1):129-153.

Alonso Araguás, Icíar y Baigorri Jalón, Jesús (2007): Lenguas indígenas y mediación lingüística en las reducciones jesuíticas del Paraguay (S. XVII). mediAzioni. 4:12p. Consultado 
el 3 de noviembre de 2018, <http://www.mediazioni.sitlec.unibo.it/index.php/no4anno2007/44-articolino3-anno2007/85-lenguas-indigenas-y-mediacion-lingueistica-en-lasreducciones-jesuiticas-del-paraguay-s-xvii.html>.

Alonso Araguás, Icíar, Baigorri Jalón, Jesús y PAyÀs, Gertrudis (2008): Nahuatlatos y familias de intérpretes en el México colonial. 1611 - Revista de Historia de la Traducción. 2:6 p. Consultado el 20 de enero de 2018, <https://ddd.uab.cat/pub/1611/19882963n2/1988 2963n2a7/alonso-baigorri-payas.htm\# $>$.

Alonso Araguás, Icíar, PÁez Rodríguez, Alba y Samaniego Sastre, Mario (2015): Traducción y representaciones del conflicto desde España y América. Una perspectiva interdisciplinar. Salamanca: Editorial de la Universidad de Salamanca.

Arencibia Rodríguez, Lourdes Beatriz (1997): Un campo intocado: un capítulo sobre las traducciones literarias del siglo XIX en Cuba. Revolución y cultura. 97(5):4-8.

Arencibia Rodríguez, Lourdes Beatriz (1998a): Un traductor llamado José Martí: una valoración necesaria. Temas. 15:96-108.

Arencibia Rodríguez, Lourdes Beatriz (1998b): ¿Por qué Martí? Anónimos, Boletín del Equipo de Servicios de Traductores e Intérpretes. 2(4):11-16.

Arencibia Rodríguez, Lourdes Beatriz (2002): ¿Por qué la traducción y por qué Martí?: Una valoración necesaria. Patria, Cuadernos de la Cátedra Martiana. 1(1):55-68.

Arencibia Rodríguez, Lourdes Beatriz (2003): El Imperial Colegio Santa Cruz de Tlatelolco: La primera escuela de traductores / intérpretes en el siglo XVI en Hispanoamérica. Revista de la Facultad de Lenguas Modernas. 6.

Arencibia Rodríguez, Lourdes Beatriz (2005): La interpretación en la América pre-hispánica ¿Fue acaso una ficción o hay que archivar el caso por falta de evidencias?’ In: María Luisa Romana García, ed. Actas del II Congreso Internacional AIETI - Formación, Investigación y Profesión. (II Congreso Internacional AIETI - Formación, Investigación y Profesión, Madrid, 9-11 de febrero de 2005). Madrid: Universidad Pontificia de Comillas, 408-414.

Arencibia Rodríguez, Lourdes Beatriz (2008a): Globalización e interculturalidad: los retos del traductor y del intérprete en América Latina. Revista de la Facultad de Humanidades y Lenguas Modernas. 11.

Arencibia Rodríguez, Lourdes Beatriz (2008b): Historiando la traducción del otro, en el viejo, en el nuevo y en todos los mundos. Revista de la Facultad de Humanidades y Lenguas Modernas. 11.

Arencibia Rodríguez, Lourdes Beatriz (2009a): El Poe que se ha leído en Cuba. En el bicentenario del nacimiento de Edgar Allan Poe. Revista de la Facultad de Humanidades y Lenguas Modernas. 12.

Arencibia Rodríguez, Lourdes Beatriz (2009b): Julio Cortázar, traductor de Poe. Revista de la Facultad de Humanidades y Lenguas Modernas. 12.

Arencibia Rodríguez, Lourdes Beatriz (2010): Heredia y De Heredia: el otro en el espejo. Revista de la Facultad de Humanidades y Lenguas Modernas. 13.

Arencibia Rodríguez, Lourdes Beatriz y Hernández Valdés, Emilio (2008): Medio siglo de traducción y edición de las literaturas anglo y franco caribeñas en Cuba. Editorial Electrónica Cubaliteraria. Consultado el 10 de enero de 2018, <http://www.cubaliteraria.com/ articulo.php?idarticulo $=8095$ \&idseccion $=55>$.

Bastin, Georges (1996): Bases para una historia de la traducción en Venezuela. Livius. 8:9-25.

BAstin, Georges (1998): Latin American Tradition. In: Mona BAKer, ed. Routledge Encyclopedia of Translation Studies. Londres: Routledge, 505-512.

BAstin, Georges (2003): Por una historia de la traducción en Hispanoamérica. Íkala. 8(14):193-217.

BAstin, Georges (2004): Traducción y emancipación: el caso de la Carmañola. Boletín de la Academia Nacional de la Historia de Venezuela. 345:199-209.

BAstin, Georges (2007): La traduction des catéchismes et la conquête spirituelle dans la Province du Venezuela. TTR. 20(1):215-243.

Bastin, Georges (2008): La traducción y la conformación de la identidad latinoamericana. TRANS. 12:11-14. 
Bastin, Georges (2009): Francisco de Miranda, intercultural forerunner. In: John Milton y Paul BANDiA, ed. Agents of Translation. Ámsterdam: John Benjamins, 19-42.

Bastin, Georges (2010): La primera traducción impresa en Venezuela. In: Juan Lanero FerNÁNDEZ y José Luis Chamosa, ed. Lengua, traducción, recepción en honor de Julio César Santoyo. León: Universidad de León, 79-92.

BAstin, Georges y CASTriLlón, Elvia (2004): La 'Carta dirigida a los españoles americanos', una carta que recorrió muchos caminos. Hermeneus. 6:276-290.

Bastin, Georges y Díaz, Adriana (2004): Las tribulaciones de la Carmañola (y de la Marsellesa) en América Latina. TRANS. 8:29-40.

Bastin, Georges y Echeverri, Álvaro (2004): Traduction et révolution à l'époque de l'indépendance hispano-américaine. Meta. 49(3):562-575.

BAstin, Georges, Echeverri, Álvaro y CAmpo Ángela (2004): La traducción en América Latina: propia y apropiada. Estudios, Revista de Investigaciones Literarias y Culturales. 24:69-94.

Bastin, Georges y Iturriza, María Gabriela (2008): La traducción como elemento creador de identidad en la prensa independentista de Venezuela (1808-1822). TRANS. 12:81-94.

Bastin, Georges, Navarro, Aura y Iturriza, María Gabriela (2010): La prensa independentista venezolana (1808-1822) desde la traducción. In: Gastón LILlo y Leandro UrbiNA, eds. De Independencias y Revoluciones. Avatares de la modernidad en América Latina. Santiago de Chile: LOM Ediciones, 193-213.

Franco Aixelá, Javier (2012): A critical overview of the Translation Studies journals published in Spain. In: Isabel García IzQuierdo y Esther Monzó Nebot, eds. Iberian Studies on Translation and Interpreting. Berna: Peter Lang, 339-361.

Franco Aixelá, Javier y Rovira-Esteva, Sara (2019): A bibliometric overview of Translation Studies research in Spanish-speaking countries. In: Roberto A. Valdeón y África Vidal, eds. The Routledge Handbook of Spanish Translation Studies. Londres/Nueva York: Routledge.

GAPPER Morrow, Sherry Elaine (2008): El desarrollo de la traducción en Costa Rica y Centroamérica. In: Fernando Navarro Domínguez, Miguel Ángel Vega Cernuda, Juan Antonio Albaladejo Martinez et al., eds. La traducción: balance del pasado y retos del futuro. Alicante: Departamento de Traducción e Interpretación de la Universidad de Alicante/ Aguaclara, 409-420.

García Albero, Javier (2008): La recepción de Mamita Yunai de Carlos Luis Fallas en Italia y Francia; entre la proximidad lingüística y la divergencia cultural. Letras. 43:193-205.

Grbić, Nadja (2008): Gebärdensprachdolmetschen im deutschsprachigen Raum. Szientometrische Befunde [Interpretación de lenguaje de señas en países de habla alemana. Hallazgos esientométricos]. In: Barbara Ahrens, Lothar Černý, Monika Krein-Kühle et al., eds. Translationswissenschaftliches Kolloquium I. Beiträge zur Übersetzungs-und Dolmetschwissenschaft (Köln-Germersheim) [Primero coloquio de estudios de traducción. Contribuciones a los estudios de traducción e interpretación (Köln-Germersheim)]. Frankfurt am Main/Berlín/Berna/Bruselas/Nueva York/Oxford/Viena: Peter Lang, 145-166.

Grbić, Nadja y Pöllabauer, Sonja (2008a): Counting what counts. Research on community interpreting in German-speaking countries - A scientometric study. Target. 20:297-332.

Grbić, Nadja y Pöllabauer, Sonja (2008b): An author-centred scientometric analysis of Daniel Gile's oeuvre. In: Gyde Hansen, Andrew Chesterman y Heidrun Gerzymisch-Arbogast, eds. Efforts and models in interpreting and translation research. Ámsterdam/Filadelfia: John Benjamins, 3-24.

Grbić, Nadja y Pöllabauer, Sonja (2008c): To count or not to count: Scientometrics as a methodological tool for investigating research on translation and interpreting. Translation and Interpreting Studies. 3:87-146.

Grupo Alfaqueque (2010): Los límites de Babel. Ensayos sobre la comunicación entre lenguas $y$ culturas. Madrid/Frankfurt: Iberoamericana/Vervuert.

Lafarga Maduell, Francisco y Pegenaute Rodríguez, Luis, eds. (2012a): Aspectos de la historia de la traducción en Hispanoamérica. Autores, traducciones y traductores. Vigo: Editorial Academia del Hispanismo. 
Lafarga Maduell, Francisco y Pegenaute Rodríguez, Luis, eds. (2012b): Lengua, cultura y política en la historia de la traducción en Hispanoamérica. Vigo: Editorial Academia del Hispanismo.

Lafarga Maduell, Francisco y Pegenaute Rodríguez, Luis, eds. (2012c): Biblioteca de Traducciones Hispanoamericanas. Madrid: Biblioteca Virtual Miguel de Cervantes.

Lafarga Maduell, Francisco y Pegenaute Rodríguez, Luis, eds. (2013): Diccionario histórico de la traducción en Hispanoamérica. Madrid: Iberoamericana/Vervuert.

LI, Xiangdong (2015): International visibility of mainland China Translation Studies community: A scientometric study. Perspectives. 23(2):183-204.

Martínez-Gómez, Aida (2015): Bibliometrics as a tool to map uncharted territory: A study on non-professional interpreting. Perspectives. 23(2):205-222.

Payás Puigarnau, Gertrudis y Zavala, José Manuel, eds. (2012): La mediación lingüísticocultural en tiempos de guerra. Cruce de miradas desde España y América. Temuco: Editorial UC Temuco.

Rodríguez Chávez, Iván (2002/2003): Importancia de la traducción literaria en el Perú. Hieronymus Complutensis. 43(9/10):193-205.

Rovira-Esteva, Sara y Orero Clavero, Pilar (2011): A contrastive analysis of the main benchmarking tools for research assessment in translation and interpreting: the Spanish approach. Perspectives. 19(3):233-251.

Rovira-Esteva, Sara y Orero Clavero, Pilar (2012): Evaluating quality and excellence in translation studies research: Publish or perish, the Spanish way. Babel. 58(3):254-288.

Rovira-Esteva, Sara, Orero Clavero, Pilar y Aixalá Javier Franco (2015): Bibliometric and bibliographical research in Translation Studies. Perspectives. 23(2):159-160.

Sanz, Ileana, Morejón, Nancy y Arencibia, Lourdes (2014): Foro: Cuba traduce el Caribe. Tusaaji. 3:88-100.

TANG, Fang (2010): A bibliometric analysis of empirical interpreting studies in China: Based on data of experimental research papers. Foreign Language World. 2:39-46.

Valero Cuadra, Pino (2008): La traducción alemana de Marcos Ramírez, de Carlos Luis Fallas. Letras. 43:157-175.

VARGas Gómez, Francisco Javier (2009): Un pájaro azul en Costa Rica: la función de la traducción de L'Oiseau bleu en la Costa Rica de 1912. Letras. 45:201-217.

VARGAS Gómez, Francisco Javier (2010): Érase una vez en Costa Rica: Breve historia de la breve historia de la traducción de la literatura costarricense. Grupo de Investigación HISTRAD. Consultado el 1 de marzo de 2017, <https://web.ua.es/es/histrad/documentos/traduccionesal-espanol/erase-una-vez-en-costa-rica-francisco-vargas.pdf > .

VARGas Gómez, Francisco Javier (2017): Los estudios de traducción en Hispanoamérica: un estudio bibliométrico de la producción publicada en revistas con filiación hispanoamericana. Mutatis Mutandis. 10(2):5-45.

Vega Cernuda, Miguel Ángel (2008a): La historia de la traducción como tarea de investigación de las letras costarricenses. Letras. 43:125-142.

Vega Cernuda, Miguel Ángel (2008b): Recepción y traducción en alemán de Mamita Yunai, de Carlos Luis Fallas. Letras. 43:143-156.

Vega Cernuda, Miguel Ángel y Pulido, Marta (2013): La historia de la traducción y de la teoría de la traducción en el contexto de los estudios de la traducción. MonTI. 5:9-38.

WANG, Binhua (2016): A bibliometrical analysis of interpreting studies in China: Based on a database of articles published in the CSSCI/CORE journals in recent years. Babel. 61(1):6277.

WANG, Binhua y MU, Lei (2009): Interpreter training and research in mainland China: Recent developments. Interpreting: International Journal of Interpreting Theory and Practice. 11:267-283.

Xu, Ziyun y Pekelis, Leonid (2015): Chinese Interpreting Studies: a data-driven analysis of a dynamic field of enquiry. PeerJ. 3. Consultado el 7 de marzo de 2017, <https://peerj.com/ articles/1249/>. 